\title{
An assessment of the Azostix strip test
}

A. M. BOLD, I. S. MENZIES, AND G. WALKER

From the Department of Chemical Pathology, St Thomas's Hospital, London

SYNOPSIS The approximate concentration of urea in a single, unmeasured drop of blood may be estimated with an Azostix strip in a little over a minute, without the use of laboratory equipment.

The test has been assessed by comparing 488 strip readings made by two observers on 331 specimens of blood from patients with plasma urea concentrations determined by the AutoAnalyzer diacetyl monoxime method. Observations were also made on inter- and intraobserver reading differences, on the effect of the period of contact of blood with the reagent zone of the strip and on the effect of different types of illumination.

Difficulties with visual colour matching inevitably limit the performance of this type of test. Azostix strips cannot replace laboratory methods, but, provided their limitations are appreciated, and proper technique is observed, they should provide a screening test for azotaemia when laboratory facilities are not readily available. Their place in hospitals would seem to be confined to emergency use as a screening test for severe azotaemia. In general and domiciliary practice they should provide a convenient screening test for azotaemia provided that readings greater than ' $20 \mathrm{mg} / 100 \mathrm{ml}$ ' are taken as an indication for further investigation.

Azostix strips have been developed by the Ames Company as a convenient, quick method for the estimation of approximate blood urea concentration without the use of laboratory equipment.

The strips consist of a reagent zone 6 by $10 \mathrm{~mm}$ attached to one end of a transparent plastic handle $8 \mathrm{~cm}$ long. The reagent zone is made of paper impregnated with urease and a $p \mathrm{H}$ indiReceived for publication 12 March 1969. cator, bromothymol blue. It is coated with a membrane which is freely permeable to urea but prevents staining of the paper by blood pigments. Estimations are performed by leaving a drop of blood on the reagent zone for 60 seconds after which it is quickly washed away and the colour of the reagent zone immediately compared with four colour chart blocks printed on the bottle label. The colour change of the indicator from yellow 
to green varies with the blood urea concentration and depends on an increase in $p \mathrm{H}$ due to ammonia liberated by the action of urease on urea which has diffused through the membrane. The colour chart blocks were originally claimed to represent blood urea nitrogen concentrations of 10, 20, 30 , and $50 \mathrm{mg} / 100 \mathrm{ml}$. From the results of this and other studies it was evident that with this scale the strips consistently underestimated blood urea concentration. The manufacturer subsequently assigned new values to the blocks and the scale, in terms of blood urea, now reads, 20, 45, 85 , and $130 \mathrm{mg} / 100 \mathrm{ml}$. As neither the strips nor the colours of the blocks have been changed we have transcribed the results of our strip test readings to the new scale thus allowing an assessment of the product as it is now marketed.

In this study results obtained with the strips on blood from patients have been compared with the urea concentrations of the corresponding plasmas determined by the AutoAnalyzer diacetyl monoxime method. Observations were also made on inter-and intra-observer differences in readings on the effect of varying the period of contact of blood with the reagent zone and on the influence of different types of illumination on strip test readings.

As there is little published information on the difference between blood and plasma urea concentrations this matter was investigated in order to be able to calculate from observed plasma values approximate mean blood urea concentrations corresponding to the different strip test readings.

\section{Method}

Azostix readings were made only by laboratory workers who were shown by the Ishihara plates to have normal colour vision. To avoid possible errors due to lack of familiarity with the test technique, before participating in the study each observer tested 50 blood specimens having plasma urea concentrations between 16 and $189 \mathrm{mg} /$ $100 \mathrm{ml}$.

Tests were performed during the summer, and, unless otherwise stated, in good daylight in front of a north-facing window but never in direct sunlight. The manufacturer's instructions were followed closely. A large drop of blood was placed on the reagent zone with a Pasteur pipette and quickly spread to cover it. After 60 seconds the blood was washed away by a jet of distilled water directed at the adjacent plastic handle so as to flow over the reagent zone. The appearance of the reagent zone was compared quickly with the colour chart blocks and the result recorded as one of nine possibilities, namely, as matching a specified block, as falling between adjacent blocks, as less than ' $20 \mathrm{mg} / 100 \mathrm{ml}$ ', or as greater than ' $130 \mathrm{mg} / 100 \mathrm{ml}$ '.
Plasma urea concentrations were determind by the AutoAnalyzer diacetyl monoxime method.

For that part of the study in which strip test results on blood from patients were compaped with plasma urea concentrations of the same specimens 488 tests were made by two observers on 331 specimens. The original specimens of heparinized blood were mixed by repeated inve्: sion, and aliquots for testing with the strips we re set aside at room temperature in capped AumoAnalyzer cups. The aliquots were generafily tested within four hours of the blood arrivitzg in the laboratory and were thoroughly re-mixed before testing. Initially blood specimens werbe unselected. Later, to ensure adequate coverge of the entire range of the test, specimens expected to have high urea concentrations were selected but were always interspersed with other specimẹns taken at random. Neither observer was told uigipil this part of the study was finished how his resudts compared with the plasma urea values or with those of his colleague. Strips from a single production batch were used throughout this part of the stuafy and for the investigation of the effect of duratien of contact of blood with the reagent zone. Strips from another batch were used for the other investigations.

Inter-observer reading differences were examined by comparing the readings obtained on the 157 clinical specimens tested by both observess. In addition 10 observers tested aliquots of a rō domized series of seven samples of blood fronfa normal subject to which different amounts of urea had been added and tested a second aliq $\overrightarrow{\mathrm{b}} \mathrm{t}$ of the same specimens three to four hours later.

Intra-observer reading differences we examined by comparing the two results obtained by each observer on each of the seven specimens in the above investigation of inter-obseryer reading differences. Further information 쁘 intra-observer variation was obtained from the results of an experiment to investigate the effect on test readings of the duration of contact of blood with the reagent zone. Three series of tests were performed by an observer using blood from a normal subject, with and without added urea. In each series five tests were made in randळ order for each of the following periods of contact of blood with the reagent zone; 30, 45, 60, and 90 seconds.

To investigate the effect of different types ${ }_{0}$ illumination on strip test readings separate aliquots of a randomized series of seven spesimens of blood containing different amounts $\mathrm{of}$ added urea were tested in daylight and three fo four hours later in artificial light. Ten observets carried out tests in daylight and in a dark ro@i beneath two shaded 80-watt 'daylight' fluorescent tubes. Eight of the observers tested anotier series of seven specimens in daylight and in the dark room 2-3 feet from a 60-watt tungsten b i in a reading lamp. The agreements betwen readings made in daylight and in the two tyees 


\begin{tabular}{|c|c|c|c|c|c|c|c|c|c|}
\hline \multirow{2}{*}{$\begin{array}{l}\text { AutoAnalyzer } \\
\text { Results (plasma } \\
\text { urea } \mathrm{mg} / 100 \mathrm{ml})\end{array}$} & \multicolumn{9}{|c|}{ Azostix Results (blood urea $\mathrm{mg} / 100 \mathrm{ml}$ ) } \\
\hline & $<20$ & 20 & $20-45$ & 45 & $45-85$ & 85 & $85-130$ & 130 & $>130$ \\
\hline 10- 19 & 15 & 15 & 6 & & & & & & \\
\hline $20-29$ & 9 & 65 & 44 & 4 & 1 & & & & \\
\hline 30- 39 & & 14 & 77 & 8 & 2 & & & & \\
\hline 40- 49 & & & 38 & 8 & 8 & 1 & 2 & & \\
\hline 50- 59 & & & 7 & 4 & 8 & 1 & 3 & & \\
\hline 60- 69 & & & 4 & & 8 & 6 & 4 & & \\
\hline 70- 79 & & & & 4 & 6 & 3 & 4 & & \\
\hline 80- 89 & & & & & 1 & 1 & 2 & 1 & 1 \\
\hline 90- 99 & & & 1 & & 3 & 3 & 3 & 1 & \\
\hline $100-109$ & & & & 1 & & & 1 & 2 & \\
\hline $110-119$ & & & & & 1 & & 2 & 4 & 1 \\
\hline $120-129$ & & & & & & & 2 & 4 & 2 \\
\hline $130-139$ & & & & & & 1 & 3 & & 1 \\
\hline $140-149$ & & & & & & & 1 & 2 & 1 \\
\hline $150+$ & & & & & & & 5 & 16 & 42 \\
\hline n & 24 & 94 & 177 & 29 & 38 & 16 & 32 & 30 & 48 \\
\hline
\end{tabular}

Table I Relationship between urea concentrations of blood estimated by Azostix strips and of plasma determined by Auto Analyzer ${ }^{1}$

${ }^{1}$ The figures represent the number of specimens with plasma urea concentrations within the ranges indicated in the left hand column which gave Azostix readings shown at the top of the table. Combined results of two observers, including 157 specimens tested by both.

\begin{tabular}{lrrrrrrr}
\hline \multicolumn{7}{l}{ Azostix } & Urea Concentration $(\mathrm{mg} / 100 \mathrm{ml})$ \\
\hline & 20 & $20-45$ & 45 & $45-85$ & 85 & $85-130$ & 130 \\
\hline Plasma & & & & & & & \\
Mean & $23 \cdot 7$ & $35 \cdot 0$ & $48 \cdot 5$ & $59 \cdot 3$ & $75 \cdot 0$ & $108 \cdot 8$ & $155 \cdot 7$ \\
SD & $5 \cdot 1$ & $9 \cdot 5$ & $6 \cdot 5$ & $18 \cdot 2$ & $22 \cdot 1$ & $54 \cdot 3$ & $84 \cdot 3$ \\
Blood & & & & & & & \\
Mean & $22 \cdot 0$ & $32 \cdot 6$ & $45 \cdot 1$ & $55 \cdot 2$ & $69 \cdot 8$ & $101 \cdot 0$ & $144 \cdot 8$ \\
SD & $4 \cdot 7$ & $8 \cdot 7$ & $6 \cdot 1$ & $16 \cdot 9$ & $20 \cdot 5$ & $50 \cdot 5$ & $78 \cdot 3$ \\
n & 94 & 177 & 29 & 38 & 16 & 32 & 30 \\
\hline
\end{tabular}

Table II Mean and standard deviation of plasma and blood urea concentrations of specimens giving different strip test readings ${ }^{1}$

${ }^{1}$ Blood urea concentration (B) calculated from plasma urea concentration $(P)$ by means of the formula $B=0.93 P$

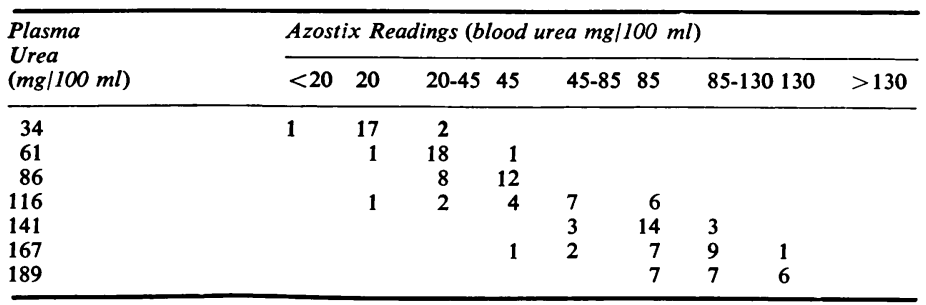

Table III Inter-observer strip test reading differences ${ }^{1}$

${ }^{1}$ Randomized duplicates of seven blood specimens were tested by 10 observers. The figures represent the number of occasions in Azostix reading corresponding to the value at the top of the column was obtained with the blood specimen the plasma concentration of which is indicated at the left hand end of the row.

of artificial light were compared with the agreement between the duplicate readings in daylight already mentioned. The statistical significance of the differences was determined by the $\chi^{2}$ test.

A comparison of blood and plasma urea concentrations was made on 51 specimens. Estimations were performed by the AutoAnalyzer diacetyl monoxime method and care was taken to ensure that the blood was thoroughly mixed immediately before sampling. The blood urew concentrations of the specimens were between 15 and $90 \mathrm{mg} / 100 \mathrm{ml}$. Haematocrit values were not measured but 20 specimens were from healthy? young adults and none of the 31 specimens frong patients showed a conspicuously low proportion of cells to plasma after centrifugation.

Results

COMPARISON OF STRIP TEST RESULTS WIT PLASMA UREA CONCENTRATIONS

Table I shows the results of 488 readings mada with strips from the first batch on 331 clinical blood specimens. There is a considerable scatter oto plasma urea concentrations corresponding to each strip test reading. This is reflected in the values of the standard deviations shown in Table II. The mean blood urea values in this table sugळ gest that for this particular batch of strips the definitive values assigned to the first two coloup blocks were satisfactory but that those assigned to the third and fourth blocks may have been to\& high and too low respectively. Table I shows tha of specimens having plasma urea concentrations of $50 \mathrm{mg} / 100 \mathrm{ml}$ (equivalent to $46 \mathrm{mg} / 100 \mathrm{~m}$ blood urea) or greater, 12 out of $171(7 \%)$ of the strip readings were less than $45 \mathrm{mg} / 100 \mathrm{mk}$ whilst of the 193 Azostix readings of $45 \mathrm{mg}$ $100 \mathrm{ml}$ ' or greater, $34(18 \%)$ corresponded to plasma urea concentrations below $50 \mathrm{mg} / 100 \mathrm{ml}$ Using the particular batch of strips tested our two observers were unable to differentiate satisfactorily between specimens with plasma ureos concentrations above and below $50 \mathrm{mg} / 100 \mathrm{mP}$ Fifty of the $177(28 \%)$ readings of ' 20 to $45 \mathrm{mg}$ $100 \mathrm{ml}$ ' corresponded to plasma urea concentras tions of $40 \mathrm{mg} / 100 \mathrm{ml}$ or greater but all 118 readings of ' $20 \mathrm{mg} / 100 \mathrm{ml}$ ' or less corresponded to plasma urea concentrations below $40 \mathrm{mg} / 100$ $\mathrm{ml}$, a value often taken as the upper limit of normal.

The results in Table III were obtained with the second batch of strips using blood from a normak subject to which different amounts of urea ha\& been added. These strips consistently under $\underline{\omega}$ estimated throughout their entire range.

INTER-OBSERVER DIFFERENCES IN STRIP TEST READINGS

Table IV shows that when 153 clinical bloof specimens were tested by two observers, observe? A frequently recorded lower readings than obser 2 ver B, particularly over the middle of the coloup chart range. A considerable scatter of readings is shown in Table III when 10 observers teste duplicate aliquots of a series of blood specimen containing different amounts of added urea 


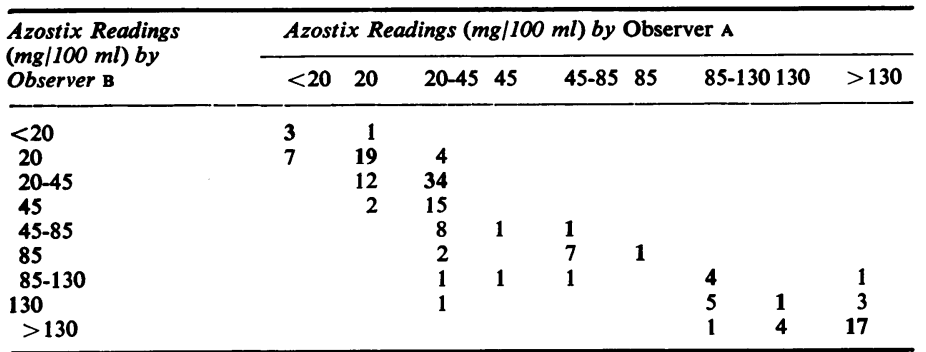

Table IV Comparison of Azostix readings obtained by two observers on the same clinical blood specimens ${ }^{1}$

'The figures represent the number of specimens to which Azostix results indicated in the top row and in the left hand column were assigned by observers $A$ and $B$ respectively. Figures in heavy type show concordant results.

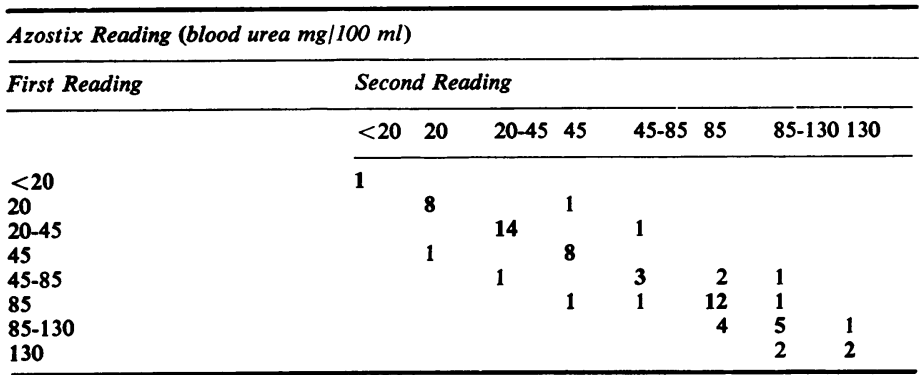

Table V Intra-observer reading differences ${ }^{1}$

${ }^{1}$ Randomized duplicates of seven blood specimens (the same as in Table IV) were tested by 10 observers. The figures represent the number of occasions on which the Azostix reading indicated at the top of the column obtained on one aliquot of a sample was associated with the reading indicated at the left hand end of the row on the other aliquot of the same sample.

\begin{tabular}{|c|c|c|c|c|c|c|c|c|c|c|c|c|c|c|c|}
\hline \multirow{3}{*}{$\begin{array}{l}\text { Azostix Reading } \\
(\mathrm{mg} / 100 \mathrm{ml})\end{array}$} & \multicolumn{15}{|c|}{ Time (in seconds) Blood Left on Reagent Zone } \\
\hline & \multicolumn{3}{|c|}{30} & \multicolumn{3}{|l|}{45} & \multicolumn{3}{|c|}{60} & \multicolumn{3}{|l|}{75} & \multicolumn{3}{|l|}{90} \\
\hline & $\boldsymbol{A}$ & $\boldsymbol{B}$ & $\boldsymbol{C}$ & $\boldsymbol{A}$ & $\boldsymbol{B}$ & $C$ & $\boldsymbol{A}$ & $\boldsymbol{B}$ & $C$ & $\boldsymbol{A}$ & $\boldsymbol{B}$ & $C$ & $\boldsymbol{A}$ & $\boldsymbol{B}$ & $\boldsymbol{C}$ \\
\hline $\begin{array}{l}<20 \\
20 \\
20-45 \\
45 \\
45-85 \\
85 \\
85-130 \\
130\end{array}$ & $\begin{array}{l}4 \\
1\end{array}$ & $\begin{array}{l}2 \\
3\end{array}$ & 5 & $\begin{array}{l}1 \\
4\end{array}$ & 5 & $\begin{array}{l}3 \\
2\end{array}$ & $\begin{array}{l}3 \\
2\end{array}$ & 5 & $\begin{array}{l}1 \\
2 \\
2\end{array}$ & 5 & $\begin{array}{l}4 \\
1\end{array}$ & $\begin{array}{l}3 \\
2\end{array}$ & $\begin{array}{l}3 \\
2\end{array}$ & $\begin{array}{l}1 \\
2 \\
2\end{array}$ & 5 \\
\hline
\end{tabular}

Table VI Intra-observer differences in Azostix readings and effect of period of contact of blood with reagent zone $e^{1}$

${ }^{1}$ The figures represent the number of Azostix readings specified in the left hand column recorded for each of the three specimens, A, B, and C, after blood had been in contact with the reagent zone for the periods indicated at the top of the table. All readings made by observer $B$ five times. Blood from normal subject $(A)$ containing different amounts of added urea (B and $C$ ) Plasma urea concentrations of the specimens: $A=30 \mathrm{mg} / 100 \mathrm{ml}$, $B=64 \mathrm{mg} / 100 \mathrm{ml}, \mathrm{C}=120 \mathrm{mg} / 100 \mathrm{ml}$.
This type of reading difference may have been due to different observers attaching differento importance to colour intensity and to hue whenf reading the tests.

INTRA-OBSERVER DIFFERENCES IN STRIP TEST READINGS

Tables V and VII show that the same results were obtained in 53 out of $70(76 \%)$ instance when duplicate specimens of blood containing different amounts of added urea were tested by 10 observers in daylight. The discordant results showed no relationship to the order of testing Intra-observer reading differences are also seen in Table VI which gives results obtained by a single observer who performed a series of tests in quinit tuplicate.

EFFECT OF PERIOD OF CONTACT OF BLOOD WITH REAGENT ZONE

The differences in the results recorded when the period of contact of blood with the reagent zone varied from 30 to 90 seconds are shown in Table VI. Better results were obtained when blood was. left on the strip for $\mathbf{9 0}$ seconds than for $\mathbf{6 0}$ second5 as recommended by the manufacturer. Much more evidence would be required before advising a change of technique.

EFFECT OF ILLUMINATION ON STRIP TEST

READINGS

Comparison of the figures in rows 1 and 2 in Table VII shows that strip test readings on differo ent aliquots of the same specimens were not significantly different in daylight and in 'daylight fluorescent light $\left(\chi^{2}=3.98\right.$ on 2 df. $\left.0.1<P<0.2\right)$ Comparison of the figures in rows 1 and 3 , how ever, shows that significantly lower readings were obtained in tungsten light than in dayligh $\left(\chi^{2}=25.0\right.$ on $\left.2 \mathrm{df}, \mathrm{P}<0.001\right)$

\begin{tabular}{|c|c|c|c|}
\hline \multirow{2}{*}{ Type of Illumination } & \multicolumn{3}{|c|}{ Azostix Readings } \\
\hline & $\bar{A}>B$ & $A=B$ & $A<B$ \\
\hline $\begin{array}{l}1 \text { A Daylight, 1st reading } \\
\text { B Daylight, 2nd reading }\end{array}$ & 10 & 53 & 7 \\
\hline $\begin{array}{l}2 \text { A Daylight } \\
\text { B Fluorescent light }\end{array}$ & 19 & 47 & 4 \\
\hline $\begin{array}{l}3 \text { A Daylight } \\
\text { B Tungsten light }\end{array}$ & 31 & 22 & 3 \\
\hline
\end{tabular}

Table VII Intra-observer Azostix reading differences and effect of type of illumination

\section{DIFFERENCES BETWEEN BLOOD AND}

PLASMA UREA CONCENTRATIONS

The relationship between blood urea (P) an plasma urea (P) concentrations for specimeis with blood urea concentrations between 15 an $90 \mathrm{mg} / 100 \mathrm{ml}$ was found to be: $\mathrm{B}=0.93 \mathrm{~m}$ correlation coefficient, $r=0.82$. 


\section{Discussion}

The differences between the performance of the two batches of strips shown in Tables I and III occurred in spite of efforts to ensure uniformity of technique throughout the study and may have been due to an inherent difference in sensitivity. It could, however, have been due, at least in part, to different methods of testing involving different sources of blood and different numbers of observers. Much further work by many observers, using strips from different production batches and comparing results with directly determined blood urea concentrations, will be required to check the performance of the product. It does, however, seem from our limited observations, that for practical purposes, strip test readings of ' $20 \mathrm{mg} / 100 \mathrm{ml}$ ' or less indicate plasma urea concentrations less than $40 \mathrm{mg} / 100 \mathrm{ml}$ and that specimens with plasma urea concentrations over 150 $\mathrm{mg} / 100 \mathrm{ml}$ generally give strip test readings of ' $85 \mathrm{mg} / 100 \mathrm{ml}$ ' or higher. In any event, a strip test reading higher than ' $20 \mathrm{mg} / 100 \mathrm{ml}$ ' should be regarded as an indication for a urea estimation by a laboratory method.

The attraction of the Azostix test is that it needs only a single, unmeasured drop of blood and gives a result at the bedside or in the consulting room in a little over a minute. The observed scatter of strip test readings on blood specimens with closely similar plasma urea concentrations, the magnitude of inter- and intra-observer reading differences and the practical limitation imposed by a maximum reading of ' $130 \mathrm{mg}$ / $100 \mathrm{ml}$ ' suggest, however, that it will find little place in hospital practice, except perhaps for emergency use as a rapid test for severe azotaemia, eg, preoperatively. In general and domiciliary practice it could be used as a convenient, on-thespot screening test to detect patients who warrant investigation by laboratory tests. In this connexion it could be used to detect azotaemia as a cause of illness and in the periodic assessment of patients who are at particular risk of becoming azotaemic, such as those with hypertension or obstructive urinary tract disease. Our experience with clinical $\underline{\complement}$ specimens suggests, however, that if all patients giving strip test readings greater than ' $20 \mathrm{mg} / \mathrm{D}$ $100 \mathrm{ml}$ ' were referred for laboratory blood or plasma urea estimations, many would be retested unnecessarily. Table I shows that $142(55 \%)$ of the 260 specimens having plasma urea concentrations below $40 \mathrm{mg} / 100 \mathrm{ml}$ gave strip test readings greater than ' $20 \mathrm{mg} / 100 \mathrm{ml}$ '.

Close attention to technique is necessary if the test is to be used to the best possible advantage. $Q$ Accurate timing of the period of contact of blood's with the reagent zone is important and the blood $\overrightarrow{0}$ must be washed off the strip quickly and com- $\overrightarrow{-}$ pletely. The application of too small a drop of ${ }_{\sigma}$ blood results in low readings and drying of the specimen which cannot then be completely washed? away and so interferes with colour matching. The test should preferably be read in good daylight. If artificial light is used a 'daylight' fluorescento tube is better than a tungsten bulb. 